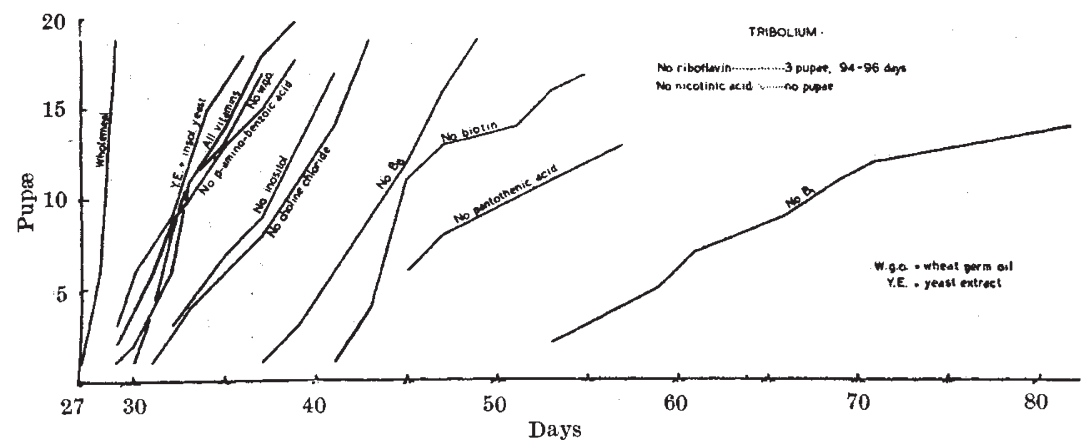
Fig. 3. Tribolium confusum. DIET CONTAINS BIOTIN INSTEAD OF INSOLUBLE YEAST.

what lesser but still great importance, inositol and $p$-amino-benzoic acid are of minor or perhaps no importance.

(8) Tribolium certainly requires no fat-soluble substance apart from a sterol (cholesterol, ergosterol, sitosterol, or 7-dehydrocholesterol, but not vitamin D) (Fig. 3). There is no evidence so far that fat, or any fat-soluble substance, apart from a sterol, is required in the diet of any insects.

These results essentially agree with and extend recent findings of other authors concerning vitamin requirements of insects. Subbarow and Trager ${ }^{2}$ demonstrated the need of the mosquito larva for $B_{1}$, riboflavin, $P_{6}$, and pantothenic acid, and Tatum $^{3}$ demonstrated that the Drosophila larva, in addition to $B_{1}$ and riboflavin, also required $B_{6}$, nicotinic acid and pantothenic acid. Galleria requires nicotinic acid ${ }^{4}$ In none of these cases did the insects grow satisfactorily without the further addition of yeast or yeast fractions. Barton-Wright's ${ }^{5}$ failure to grow Tribolium satisfactorily on artificial diets must have been due to absence of pantothenic acid, choline and perhaps other minor factors from his diet, which may also have been very low in biotin. In sharp contrast to our findings, and those of others, are the recent claims of Rosenthal and Reichstein ${ }^{6}$, according to which $\mathrm{B}_{1}$, nicotinic acid and biotin are the only B-factors required by Tribolium. These differences of results are, in our view, due rather to the use of insufficiently purified ingredients in the diet of these authors than to differences in the insect stocks or to contamination of diets by microorganisms.

We gratefully acknowledge a Government grant, made by the Royal Society, which, partly, made this investigation possible.

1 Fraenkel, G., and Blewett, M., NAture, 150, 177 (1942).

¿ Subbarow, Y., and Trager, W., J. Gen. Physiol., 23, 561 (1940).

s Tatum, E. L., Proc. U.S. Nat. Acad. Sci., 27, 193 (1941).

- Rubinshtein, D. L., and Shekun, L. A., Bull. Biol. Med. Exper. (1941).

${ }^{5}$ Barton-Wright, E., NATURE, 148, 565 (1941).

- Rosenthal, H., and Reichstein, T., Nature, 150, 546 (1942).

\section{PHYSICAL FITNESS OF SCHOOL CHILDREN IN SOUTH AFRICA}

T HE population of the Union of South Africa is slightly more than ten millions, of which about one fifth are of European stock. The others, comprising seven million aboriginal Bantus, a quarter of a million Asiatics (Indians and Chinese) and about a million 'coloureds' (that is; Eurafrieans and
Eurasians) on the whole exist at a lower socio-economic level than the bulk of the white population. Nearly a fifth of the Europeans fall into the category of 'poor whites'people who, from one cause or another, have lost their sense of responsibility. In fact, they are below the aboriginal race in physique and in general nutritional level. The 'poor white' problem in the Union was investigated in 1929 , by Murray, for the Carnegie Commission, and his report, pub. lished in 1932, so shocked the amour propre of the Government of the Union that, in 1937, it instituted a survey of the state of nutrition of the school children throughout the Union. The results of this survey so far published are scattered through various journals or appear in special reports. In order to make the methods and results of the survey more available, further studies are to be published biannually in a new journal called Manpower, the first number of which has recently reached Great Britain*. It contains, besides a very thoughtful and thoughtprovoking editorial, two original papers by $\mathbf{E}$. $\mathbf{H}$. Cluver, E. Jokl and T. W. de Jongh-authors already well known for their researches on nutrition in the Union and for a monumental work on the results of a rehabilitation service for young men.

The first of these articles, on "A National Manpower Survey of South Africa", deals with "The Principle of Physical Performance Grids" while, in the second article, a comparison is made between the physical efficiency standards of Bantu, Chinese 'Coloured', European and Indian children by the use of these 'grids'. In order to "arrive at a basic system of co-ordinates which can serve as an objective interpreter of any subsequent results of individual or group tests which may be conducted with samples of school children of all ages between 6 and 18 years, tests had to be selected which were purely objective, which could be applied simply and universally and which would give information of distinct physiological significance". The three performance components, skill, endurance and strength, were estimated by the time taken to run 100 yards and 600 yards, and the distance over which a $12 \mathrm{lb}$. shot could be thrown respectively.

Fault could be found with this choice in that the tests do not solely measure the performance com. ponents specified. Other factors intervene. Further, anyone who has had experience in assessing the physical fitness of children will realize how difficult it is to get wholehearted co-operation from all subjects, especially from those at the two extremes of the social and intelligence scales. The sophisticated are bored and are apt to treat the tests as a joke, while the less intelligent do not try their best. The lower socio-economic classes are generally suspicious of any test. The authors, however, as their tables and graphs show, have succeeded in gaining the co-operation of the majority of their subjects. Their results are statistically valid except perhaps for the Chinese children, but one hesitates at this stage to accept all the conclusions drawn from the results.

* Manpower (Volkskragte): a Biannual Scientific Journal, Vol. 1 , No. 1. Issued by the National Advisory Council for Physical Education, Pretoria. 78 . 
The authors themselves feel this and state, "We are clearly aware of the elementary nature of our experimental material. The present evidence will have to be extensively supplemented before it can be expected to act as a scientific guide to the physical education profession".

The attempt to carry out large-scale tests of skill, endurance and strength is courageous, and further papers are promised from this source in which these tests will be correlated with somatometric and other measurements. The difficulties of any wholesale methods are appreciated, but the problem facing the health services in South Africa is urgent. The same problem with the same urgency faces us in Great Britain. We have our 'poor whites' and they, like those of the Union, have a high birth-rate and a high infant death-rate, but because they are not compared with a black indigenous race, it is difficult to make the ordinary citizen aware of the difficulties and dangers to the nation of this submerged tenth which, if it maintains its present fertility, will be about a third of the next generation.

The second paper applies the 'grids' worked out in the first paper to the various races found in the Union. The authors do not say how many of the Europeans tested fell into the 'poor white' category, but they certainly weight the result. "In spite of the generally known deficiencies in their environment, in spite of their poor housing conditions, in spite of their bad food, in spite of the manifest insufficiencies of their health services and their education, the Bantu's physical abilities are superior to those of the European's". This superiority is consistent in the girls but variable in the boys. From 12.5 years to 18 the European boy is the equal and generally the superior of the Bantu in the 100 yards and 600 yards race, while at all agas he shows greater strength (putting $12 \mathrm{lb}$. shot).

From a third article, by P. J. Kloppers, entitled "Personality, Disease and the Social System", we cull the following significant sentence. "It may in truth be said that it is more important to know what kind of a man has a disease than what kind of a disease a man has".

The remaining sixteen pages are devoted to an illustrated review of the literature of man-power studies, both current and classical, ranging from "Animated Statistics", taken from Neurath's "Modern Man in the Making", to reproductions of postage stamps which picture various sports.

\section{Burns}

\section{WALNUT TREES}

\section{BY ALEXANDER L. HOWARD}

C YORRESPONDENCE appeared in The Times on 1 the subject of walnut trees some years ago, and has now been revived by an article by Sir Stephen Tallents, published in the Spectator on January 22.

As some of the correspondents in The Times expressed the mistaken opinion that walnuts could not be grown advantageously in England, and also as the majority of trees of any size or quality have been felled in the course of the last twenty years for commercial use of the wood, it would seem desir- able to direct attention to the importance of replanting.

This should be carried out in the interests both of the fruit and the timber. Through ignorance and want of care, perhaps the larg sst number of those who possess trees have failed to reap a harvest of good walnuts during the last fifty years, but that it is possible to produce equally good quality throughout England and Wales with that provided in Europe is without doubt. To secure a crop of nuts the same attention should be paid to the trees as the owner would pursue in the annual production of other fruits or flowers. The walnut tree needs to be protected from those insects which attack it, and the animals which eat the fruit on the trees, namely, tree rats, squirrels, and birds.

From the time of John Evelyn until a little more than a hundred years ago the planting of walnuts was pursued with vigour throughout England, but by degrees both practice and interest in the subject have insensibly faded away, and in only a few cases has any planting been carried out.

It is evident from very superficial observation that the planting of walnuts in Evelyn's time was general with all classes, poorer or richer. The traveller throughout Kent, by way of Sussex, through Hampshire, Dorset, and down to Somerset and Devonshire, will continue to find walnut trees adorning not only the greater or manor houses, but also villages and the gardens of country cottages.

Unfortunately, during the last fifty years all the larger trees have been eagerly sought for, and however reluctantly, eventually sold to the dealer, who has discovered the great value which the wood possesses. No other timber tree has been in such regular demand, or consistently brought the owners such a high reward during the last century.

John Evelyn's praise of the Virginian black walnut (Juglans nigra) has often been quoted. This tree is perhaps in its maturity more attractive than the European (Juglans regia), and therefore found favour with Evelyn, who probably did not live long enough to find the disadvantag $ə$ s of attempting to establish it in England, where it is difficult to rear in large numbers. Individual splendid specimens could be found, many of which are noted in Elwes and Henry's "Trees of Great Britain and Ireland" ; but inquiry will reveal that they are isolated specimens which, on account of their protected positions, have prospered. The tree grows rapidly in its early life, but does not thrive in the cold damp elimate of Great Britain, often failing to harden off its autumn growth in the winter unless in a protected position. These disadvantages do not apply to the European variety, which when grown in England and cared for will compete favourably, both in regard to the timber and the nuts, with the American variety.

It has been found possible to rear trees which had grown to a height of 5-8 ft., and occasionally more, with a girth of $4 \frac{1}{2}-5$ in. at two feet from the ground, in four years.

The increased knowledge which has resulted from experimental research work carried out at East Malling has shown that a crop can be expected within a less period of time than was formerly thought possible.

In her generosity Nature has provided us in England with opportunities for the provision of useful fruit and valuable timber : it should be our pleasure and indeed duty to take the fullest possible advantage of these opportunities which she offers. 